\title{
Primary mediastinal tumours in Iceland 1956-70
}

\author{
JÓN G. HALLGRÍMSSON \\ Department of Thoracic Surgery, University Hospital, Reykjavik, Iceland
}

\begin{abstract}
Seventeen histologically proved cases of primary mediastinal tumours were diagnosed in Iceland in 1956-70, during which period the average population was 180,000 . Sixteen of these cases, seen at the Department of Thoracic Surgery, Landspítalinn, Iceland, are analysed.

The patients' ages ranged from 1 to 59 years; 6 were males and 10 were females. Their symptoms are described. The commonest histological types were cysts $(31.2 \%)$ followed by lesions of lymphatic origin $(25 \%) ; 62.5 \%$ of the tumours were benign and $37.5 \%$ malignant. The commonest sites were the anterior and posterior compartments where $62.6 \%$ of the tumours were located. Radical excision was performed in 11 cases, partial excision in one case, and biopsy of the mediastinal tumour in five cases. There were no postoperative deaths. Further details of each case are given and the fates of the patients have been traced.
\end{abstract}

Primary mediastinal tumours of various origins are relatively uncommon but interesting and important lesions. The fact that many of them are malignant and that malignant changes occur in some of the benign tumours stresses the importance of early diagnosis and excision. Limitation of the pulmonary reserve by space occupation and by compression on the tracheobronchial tree may produce distressing complications with atelectasis, infection, and suppuration as a consequence. Infective complications in some of the types is a further reason for the early diagnosis and treatment of these lesions.

The purpose of this study is to examine the frequency, the histological classification, and the clinical features of primary mediastinal tumours in Iceland. As practically all such lesions in the country have been referred to this unit, our series is believed to represent closely the true frequency and distribution of these tumours in Iceland.

Seventeen histologically proved cases of primary mediastinal tumours were diagnosed during the 15 years 1956-70. The average population during that period was 180,000 .

\section{MATERIAL AND METHODS}

This study is based on 16 patients with histologically proved primary mediastinal tumours who were admitted to the Department of Thoracic Surgery, University Hospital (Landspítalinn), Reykja vík, during the 15-year period 1956-70. The histological diagnosis has been reviewed and the clinical and radiological states of the patients are known.
Retrosternal goitre has not been included, as there was no case of a thyroid lesion which was completely intrathoracic. This agrees with the classification of le Roux (1962) and Boyd and Midell (1968). Tumours of lymphatic origin have been included only when the first evidence was in the form of a mediastinal lesion for which thoracotomy and biopsy were undertaken to establish the histological diagnosis. None of the patients had detectable clinical evidence of involvement elsewhere at the time of surgery. This again is in accordance with the findings of Boyd and Midell (1968) and Sabiston and Scott (1952).

The patients' ages ranged from 1 to 59 years; 10 were less than 25 years. There were 6 males and 10 females.

Seven $(70 \%)$ of the females had benign lesions as compared with $3(50 \%)$ of the males.

SYMPTOMS The commonest symptom was cough in nine $(56.3 \%)$ followed by pain in the chest in eight $(50 \%)$ patients (Table I). The only significant difference between the symptoms associated with the benign and malignant lesions was that four $(80 \%)$ of the five patients who complained of weakness had malignant lesions. Four patients $(25 \%)$ had no symptoms at all; three of these lesions were

T A B LE I SYMPTOMS FROM-MEDIASTINAL TUMOURS

\begin{tabular}{|c|c|c|c|c|}
\hline & & Benign & Malignant & Total \\
\hline $\begin{array}{l}\text { Cough } \\
\text { Pain in chest } \\
\text { Fever } \\
\text { Dyspnoea } \\
\text { Weakness . . } \\
\text { Expectoration } \\
\text { No symptoms }\end{array}$ & $\begin{array}{l}\cdots \\
\cdots \\
\cdots \\
\cdots \\
\cdots\end{array}$ & $\begin{array}{l}6 \\
4 \\
3 \\
3 \\
3 \\
1 \\
2 \\
4\end{array}$ & $\begin{array}{l}3 \\
4 \\
3 \\
2 \\
4 \\
1 \\
1 \\
0\end{array}$ & $\begin{array}{l}9(56.3 \%) \\
8(50 \%) \\
6(37.5 \%) \\
5(31 \cdot 3 \%) \\
5(31 \cdot 3 \%) \\
3(18.8 \%) \\
4(25 \%)\end{array}$ \\
\hline
\end{tabular}


found on routine radiography and one was found after radiography for a fractured clavicle; all were benign lesions. There was no significant relation between the symptoms and the site of the tumour within the mediastinum.

CLASSIFICATION Cysts are the most common lesion, five $(31.2 \%)$, followed by tumours of lymphatic origin, four $(25 \%)$. Ten $(62 \cdot 5 \%)$ of the tumours were benign and six $(37.5 \%)$ malignant (Table II).

T A B LE II

HISTOLOGICAL CLASSIFICATION OF MEDIASTINAL TUMOURS

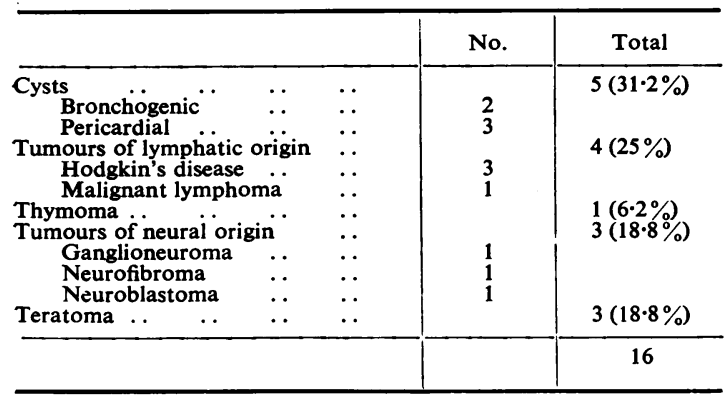

SITE The anterior and posterior compartments were the commonest sites of the tumours where $10(62.6 \%)$ were located, five in each compartment. Furthermore, most of the lesions were located according to their known predilection for certain mediastinal sites.

In all cases classical posterolateral thoracotomy was performed. There were no postoperative deaths. Apart from two patients who had minor wound infections the postoperative period was uneventful.

\section{RESULTS}

MEDIASTINAL CYSTS All the cysts were benign and all were excised radically.

Pericardial cysts were the most common (three cases); all were in women, aged 52, 53, and 54 years respectively. One was asymptomatic, the others had chest pains and cough, and one of these complained also of dyspnoea and weakness (unlikely to be due to the lesion). All the cysts were located in the pericardiophrenic angle, two on the right and one on the left side. One of the cysts measured $9 \times 4 \mathrm{~cm}$, another $8 \times 5 \mathrm{~cm}$ and the capsule of the third cyst $12 \times 4 \mathrm{~cm}$. There were two bronchogenic cysts, one in a 33-year-old man who was asymptomatic and the cyst had been found on radiographic examination 20 years previously. The lesion had not changed; it measured about $4 \mathrm{~cm}$ in diameter and was located posterosuperiorly on the right side. The other patient, a girl aged 1 year, had had recurrent fever $\left(39-40^{\circ}\right.$ C) and cough; she developed a right-sided pleural effusion and pneumothorax which recurred after repeated aspiration and she was therefore operated on. At operation a cyst was found on the right side which had almost completely compressed the lower lobe; a lower lobectomy was necessary and included the cyst which measured $4-5 \mathrm{~cm}$ in diameter. Both bronchogenic cysts showed typical histological appearances.

TUMOURS OF LYMPHATIC ORIGIN There were four tumours originating from lymphatic tissue; a biopsy was done but no attempt was made to excise the lesion. Three of the tumours were located in the superior and one, a malignant lymphoma, was located in the anterior mediastinum. Two pathological entities were found: three patients had Hodgkin's disease-two men aged 22 and one boy aged 15 years; all were symptomatic at the time of surgery. Asthenia was present in all three, two had dyspnoea as the main symptom and two complained of cough. They were given radiotherapy combined with cytotoxics. One has survived for more than six years, another died after five years, and the third is alive two years after biopsy. Another, a 22-yearold woman, had a malignant lymphoblastic lymphoma. Asthenia, pain in the chest, and fever were her main symptoms. She survived one year.

тнумомА A 46-year-old woman complained of central chest pain radiating into the throat. The tumour was excised radically from the anterior mediastinum; it weighed $60 \mathrm{~g}$ and measured $7.5 \times 7.4 \mathrm{~cm}$; it was encapsulated. As there was some invasion of tumour cells into the capsule the tumour was considered potentially malignant and was therefore classified with malignant tumours according to Bergh, Rosengren, and Seeman (1968). The patient had no symptoms of myasthenia gravis, and there were no signs of Cushing's syndrome, nor was there any aplastic anaemia, sometimes reported as co-existing with thymoma (Sawyers and Foster, 1968). More than four years later she is well, and radiography of the chest shows no sign of a recurrence of the tumour. It is of interest that this was the first thymoma to be operated on in Iceland.

TUMOURS OF NEURAL ORIGIN There were three such tumours, all located in the posterior mediastinum. Two were benign and one was malignanta neuroblastoma in a 17-year-old girl. The patient received postoperative radiotherapy, but she died 
16 months after operation. A second tumour, a ganglioneuroma in a 9-year-old girl, was a huge tumour reaching from the thoracic inlet to the diaphragm. It extended into the spinal canal through the sixth intervertebral foramina as an hour-glass extension. A thoracotomy was performed, but a radical incision was not possible, and the patient showed symptoms of compression of the spinal cord with paraplegia. A second operation, exploration of the spinal canal and excision of the tumour, was carried out, after which the paraplegia disappeared completely within a fortnight. Thirteen years later she is well, but a radiograph of the chest shows evidence of a recurrence in the mediastinum. These two cases were symptomatic-pain in the chest with the malignant tumour, and fever in both cases. The third patient was asymptomatic, a 10-year-old boy, whose neurofibroma was discovered on radiography for a fractured clavicle.

TERATOMAS There were three cases, a 59-year-old woman, an 18-year-old boy, and a 17-year-old girl. These tumours were all in the anterior mediastinum. Each tumour contained elements derived from all three germ layers. One was asymptomatic, the others had pain in the chest, cough, and dyspnoea, with repeated fever attacks in one. All the teratomas were benign; one measured $13 \times 5 \times 9 \mathrm{~cm}$, another $6 \times 5 \times 4 \mathrm{~cm}$, and the third was described as being the size of a 'goose egg.' On follow-up 2 years, 8 years, and 13 years later, respectively, they were all well and there were no signs of recurrence of the tumour on radiographic examination of the chest.

\section{DISCUSSION}

All malignant lesions were symptomatic and $60 \%$ of the benign lesions in this series. As is seen in Table I, the differences in symptoms between these two groups, with two exceptions, is insignificant. This has also been pointed out by Sabiston and Scott (1952) and later by Boyd and Midell (1968). Nor is there any significant difference in symptoms according to the site of the lesion in this series.

Early exploratory thoracotomy of a mediastinal lesion was recommended by Alexander (1942) and supported by le Roux (1962) and Boyd and Midell (1968) and many others, as malignant changes are sufficiently common in some of the lesions and because of complications caused mainly by compression of the tumour. Furthermore, it is not possible in many cases to predict the histological features of a mediastinal lesion or its operability in spite of special investigations such as mediastinoscopy and thoracoscopy. These two investigations were not used in this hospital until recently. Ten $(62.5 \%)$ of the patients in this series were operated on six months or less after diagnosis, the longest duration being 20 years in one case.

There is no general agreement about the commonest tumour in the mediastinum, and it seems that four histologically different types are the most common in the various reported series-neural tumours, cysts, lymphatic lesions, and teratomas. The frequency is also influenced by the mode of classification of the mediastinal lesions, as can be seen by comparing the papers by Sabiston and Scott (1952), le Roux (1962), and Boyd and Midell (1968). Sabiston et al. include tumours of lymphatic origin in their series; so also do Boyd and Midell. Their example is followed in the present series. Furthermore, Sabiston and Scott divided teratomas into dermoid cysts and teratomas, but le Roux combined dermoid cysts with teratomas. It is clear that this difference in classification makes comparison of the various series difficult. Heuer and Andrus (1940) stated that the group designated as dermoids or teratomas are 'by far the commonest tumours of the mediastinum' Blades (1946) found that neurogenic tumours were the commonest, closely followed by bronchogenic cysts. Brewer and Dolley (1949), Sabiston and Scott (1952) and le Roux (1962) all found neurogenic tumours most common. Bradford, Mahon, and Grow (1947) reported the experience from one hospital, where more pericardial cysts had been seen than any other type of mediastinal neoplasm. Finally, Boyd and Midell (1968) found mediastinal cysts the most common (36\%) mediastinal lesion. This agrees with the frequency found in our series, where cysts comprised $31.2 \%$ of the mediastinal lesions, followed by lesions of lymphatic origin $(25 \%)$.

It is well known that different histological types of mediastinal tumours have a predilection for certain subdivisions of the mediastinum, and the tumours in this series seem to follow that rule. On the other hand, this is by no means infallably so and the treatment should not be influenced by the site alone or the probable nature, if unconfirmed. This has been stressed by many authors (Alexander, 1942; Sabiston and Scott, 1952; Ochsner and Oschner, 1966; Boyd and Midell, 1968).

Although the small number of primary mediastinal tumours presented in this series might not have any statistical significance, the clinical and histological features bear a striking resemblance to those of many other larger reported series in the same field. 
I am indebted to H. Thorarinsson, head of the Department of Thoracic Surgery, for permission to use his material.

\section{REFERENCES}

Alexander, J. (1942). Circumscribed intrathoracic neoplasms. J. Amer. med. Ass., 119, 395.

Bergh, N. P., Rosengren, B., and Seeman, T. (1968). Treatment of tumors of the thymus. Scand. J. thorac. cardiovasc. Surg., 2, 65.

Blades, B. (1946). Mediastinal tumors. Report of cases treated at the Army Thoracic Surgery Centers in the United States. Ann. Surg., 123, 749.

Boyd, D. P., and Midell, A. I. (1968). Mediastinal cysts and tumors. An analysis of 96 cases. Surg. Clin. N. Amer., 48, 493.
Bradford, M. L., Mahon, H. W., and Grow, J. B. (1947). Mediastinal cysts and tumors. Surg. Gynec. Obstet., 85, 467.

Brewer, L. A., III, and Dolley, F. S. (1949). Tumors of the mediastinum. Amer. Rev. Tuberc., 60, 419.

Heuer, G. J., and Andrus, W. DeW. (1940). The surgery of mediastinal tumors. Amer. J. Surg., 50, 146.

le Roux, B. T. (1962). Cysts and tumors of the mediastinum. Surg. Gynec. Obstet., 115, 695.

Ochsner, J. L., and Ochsner, S. F. (1966). Congenital cysts of the mediastinum. 20 year experience with 42 cases. Ann. Surg., 163, 909.

Sabiston, D. C., Jr., and Scott, H. W., Jr. (1952). Primary neoplasms and cysts of the mediastinum. Ann. Surg., 136, 777.

Sawyers, J. L., and Foster, J. H. (1968). Surgical treatment of thymomas. Arch. Surg., 96, 814. 